\title{
KORIŠTENJE ONLINE REZERVACIJSKIH SUSTAVA U AGROTURIZMU ISTRE ${ }^{4}$
}

\section{SAŽETAK}

Rad se bavi primjenom IKT-a u turizmu, odnosno istražuje uporabu online rezervacijskih sustava kod ponude smještajnih kapaciteta u segmentu agroturizma i ruralnih obiteljskih hotela u Istri. Ciljevi istraživanja su uturditi kako vlasnici agroturizma i ruralnih obiteljskih hotela prodaju svoje smještajne kapacitete i upravljaju rezervacijama, koje online rezervacijske sustave koriste i jesu li zadovoljni njima. U teorijskom dijelu rada iznose se prednosti uporabe IKT-a u poslovnim procesima iz oblasti turizma, s naglaskom na informatizaciju ureda za rezervacije hotelskih smještajnih kapaciteta i pojave online rezervacijskih sustava. Razmatraju se prednosti uporabe online rezervacijskih sustava kako za poslovne subjekte tako i za krajnje korisnike. Relevantna istraživanja ukazuju na porast tržišta online rezervacija diljem svijeta, što se odražava i na hrvatski turizam. No u ponudi najpoznatijih online rezervacijskih sustava, poput Booking.com, TripAdvisor, Expedia, Hotels.com, Agoda i drugih, najviše je zastupljen hotelski smještaj, zatim privatni apartmani, a najčešće ne postoji kategorija za pretraživanje objekata agroturizma i ruralnog turizma. Za razliku od njih, Airbnb.com nudi isključivo privatni smještaj. Upravo njega vlasnici agroturizma i ruralnih obiteljskih hotela u Istri najviše koriste za distribuiranje vlastite turističke ponude i prodaju smještajnih kapaciteta, a slijede Booking.com i TripAdvisor. Ovo istraživanje pokazalo je da su kapaciteti objekata agroturizma i ruralnih obiteljskih hotela u Istri u velikoj mjeri dostupni na internetu putem vlastitih mrežnih stranica, te je $84 \%$ takvih objekata moguće rezervirati internetom. Ispitanici su iskazali visoko zadovoljstvo korištenim online rezervacijskog sustava, iako velik udio njih vodi evidenciju rezervacija i u papirnatom obliku.

Ključne riječi: agroturizam, online rezervacijski sustav, Booking.com, Airbnb, TripAdvisor

\section{UVOD}

Turizam utječe na gospodarski razvoj zemlje, a udio prihoda od turizma u ukupnom BDP-u Hrvatske za 2015. godinu iznosio je 18,1 \% te pokazuje tendenciju rasta (Ministarstvo turizma Republike Hrvatske, 2016). Važno je, stoga, biti ukorak s globalnim trendovima $u$ tom sektoru, pogotovo kad je riječ o manjim obiteljskim objektima sa specifičnom turističkom ponudom. Istra prednjači u segmentu ruralnog turizma, nastojeći valorizirati tradicijsko i kulturno nasljeđe, spasiti sela od propadanja, obogatiti turističku ponudu i rasteretiti obalno područje. „Prema definiciji Vijeća Europe ruralni

\footnotetext{
Mr. sc., viši predavač, Veleučilište u Rijeci, Vukovarska 58, 51000 Rijeka, Hrvatska. E-mail: elena@veleri.hr

Bacc. oec., E-mail: zupicicluana@gmail.com

3 Mr. sc., viši predavač, Veleučilište u Rijeci, Vukovarska 58, 51000 Rijeka, Hrvatska.

E-mail: jasminka.tomljanovic@veleri.hr

4 Datum primitka rada: 15. 1. 2017; datum prihvaćanja rada: 15. 2. 2017.
} 
turizam je turizam na seoskom području sa svim aktivnostima koje se provode na tom području. Prednosti ruralnog turizma su upravo njegove najznačajnije karakteristike, a to su mirna sredina, odsutnost buke, očuvani okoliš, komunikacija $s$ domaćinima, domaća prehrana, upoznavanje seljačkih poslova." (Sarjanović, 2004) U fokusu ovog rada su vlasnici agroturizama i ruralnih obiteljskih hotela u Istri, odnosno njihovo korištenje online rezervacijskih sustava koji im omogućuju globalno distribuiranje vlastite turističke ponude, stalnu dostupnost (24/7) usluge, fleksibilno upravljanje cijenama i rezervacijama $\mathrm{u}$ virtualnom okruženju te interakciju s posjetiteljima koja potiče prodaju. Pojam agroturizam odnosi se na turističku ponudu domaćinstava gdje se osim smještaja nudi i gastronomska ponuda jela iz vlastite poljoprivredne proizvodnje. Ruralni obiteljski hoteli su mali, intimni hoteli koji se nalaze na starim seoskim imanjima, tzv. „stancijama“, a osim smještajnih kapaciteta nude domaće gastronomske specijalitete, vinski podrum s vinima lokalnih proizvođača i personalizirane usluge uz neposrednu interakciju gost - domaćin. Najpoznatiji online rezervacijski sustavi koji se razmatraju u radu su: Adriagate, Adriatic.hr, Agoda, Airbnb, Booking, Expedia, Hotels.com i TripAdvisor.

\section{INFORMACIJSKA I KOMUNIKACIJSKA TEHNOLOGIJA U TURIZMU}

Brz razvoj informacijske i komunikacijske tehnologije (IKT) utječe na turistički sektor i način ponašanja turista. IKT je postao potpora mnogim poslovnim procesima u turizmu i ugostiteljstvu, te je značajno pridonio njihovoj učinkovitosti i modernizaciji. „Tehnologija danas prati korisnika - turista u svim fazama ciklusa prodaje i konzumacije turističkog proizvoda: prilikom informiranja i izbora odredišta, donošenja odluke i pripreme za putovanje, za vrijeme konzumacije turističkog proizvoda te nakon provedenog putovanja“ (Kliček, 2008). Najranija primjena IKT-a u turizmu seže u rane 60-e godine 20. st. kada su se počeli koristiti turistički rezervacijski sustavi koji su razvojem interneta evoluirali u online i rezervacijske sustave temeljene na mobilnoj tehnologiji. Upotreba rezervacijskih sustava jedan je od oblika elektroničkog poslovanja koji ubrzava poslovne procese u turističkim i uslužnim djelatnostima, a prvi su ih počeli koristiti veliki hotelski lanci. Važnost rezervacijskih sustava ogleda se $u$ tome što se pojavljuju kao sustavi online baza podataka koji turističkim organizacijama, hotelskim poduzećima i lancima te ugostiteljskim objektima omogućuju bolje upravljanje kapacitetima i njihovu veću dostupnost kroz različite kanale distribucije.

Eurostatov izvještaj o uporabi IKT-a u turizmu potvrđuje da je internet jedan od glavnih komunikacijskih kanala za turistički sektor (Eurostat, 2016). To znači da je za hrvatske turističke i ugostiteljske subjekte izuzetno važno biti prisutan na globalnom virtualnom tržištu. Prema podacima Državnog zavoda za statistiku, u 2015. godini je čak $55 \%$ korisnika interneta u Hrvatskoj koristilo internet za „usluge putovanja i smještaja“, od čega je njih $18 \%$ na taj način kupilo smještaj, tj. provelo online rezervaciju (Državni zavod za statistiku RH, 2015). U ljeto 2014. godine od svih gostiju u Hrvatskoj koji su unaprijed rezervirali smještaj 73 \% je to učinilo internetom (Vrdoljak-Šalamon, 2015). 
Prednosti uporabe IKT-a u turističkom sektoru ogledaju se ponajviše u:

- izravnom kontaktu s klijentima: rezervacije, prijave/odjave, plaćanje

- $\quad$ komunikaciji s kupcima i partnerima

- novim i personaliziranim uslugama za klijente

- $\quad$ istraživanju tržišta i marketingu

- reakciji i upravljanju neočekivanim događajima

- fleksibilnom i dinamičnom određivanju cijena

- upravljanju poslovnim procesima i osobljem te smanjenju troškova (Kliček, 2008).

Model online prodaje može se ugraditi na vlastito mrežno mjesto, može se koristiti ponuda online turističkih posrednika ili online rezarvacijskih sustava.

\section{1 Online rezervacijski sustavi}

„Rezervacija je praksa u prometu i turizmu da se unaprijed osigura buduća uporaba nekog mjesta ili pogodnosti, kao što su soba u hotelu, mjesto u zrakoplovu ili drugom prometnom sredstvu i slično" (Ružić et al., 2013). Prije informatizacije hotelskog poslovanja za provedbu rezervacije bilo je neophodno koristiti turističku agenciju kao posrednika. U suvremenom hotelijerstvu poslovi i aktivnosti vezane uz rezervaciju smještaja vode se specijaliziranim informacijskim sustavom koji osigurava:

- $\quad$ selekciju rezervacija (po vrstama i vremenu),

- potvrdu i otkazivanje rezervacija,

- odgovarajuću korespondenciju,

- izvještaje o rezervacijama,

- detalje o gostima uključujući njihove primjedbe i prijedloge,

- detalje o primljenim akontacijama i dr. (Galičić et al., 2005).

Online rezervacijski sustav je „centralni rezervacijski sustav za direktno rezerviranje i naplatu internetom, namijenjen smještajnim objektima svih veličina i tipova“" (BookingIT, 2007). Rezervacija se provodi u realnom vremenu pa krajnji korisnik može vidjeti stvarno stanje slobodnih smještajnih kapaciteta u određenom objektu, za odabrane datume. Takav servis omogućava gostu rezerviranje odabranog smještaja bez posrednika, $u$ bilo kojem trenutku, bez obzira na vremenske zone i radno vrijeme hotela. Online rezervacijski sustavi počeli su se razvijati početkom 90 -ih godina prošlog stoljeća, a prvenstveno su bili namijenjeni rezervaciji hotelskog smještaja. Danas takvi sustavi objedinjuju funkciju marketinga, prodaje i odnosa s klijentima u zajedničku tehnološku infrastrukturu s višejezičnim sučeljem. Oni imaju promotivnu funkciju jer nude različite oblike informacija o objektu, a posjetitelji mogu ostaviti komentare i napisati 
recenziju. Online rezervacijski sustavi potrošaču daju potpunu kontrolu nad onime što želi kupiti jer omogućuju pretraživanje smještajnih kapaciteta po različitim kriterijima, usporedbu cijena, uvid u recenzije ostalih posjetitelja, foto galeriju i videozapise, interaktivnu mapu te provedbu rezervacije iz udobnosti vlastitog doma, bilo koji dan u tjednu (24/7). Za provedenu online rezervaciju postoje različite mogućnosti plaćanja te mogućnost otkazivanja rezervacije do predviđenog roka bez naplate.

Najpoznatiji i najkorišteniji globalni online rezervacijski sustavi su: Booking.com, TripAdvisor.com i Expedia.com, što prikazuje graf 1. Riječ je o online rezervacijskim sustavima s bazom na internetskom poslužitelju. Samo Booking.com, Agoda.com i Hotels. com imaju sučelje i sadržaj preveden na hrvatski jezik.

Graf 1. Popularnost online rezervacijskih sustava 2014. godine prema broju posjetitelja

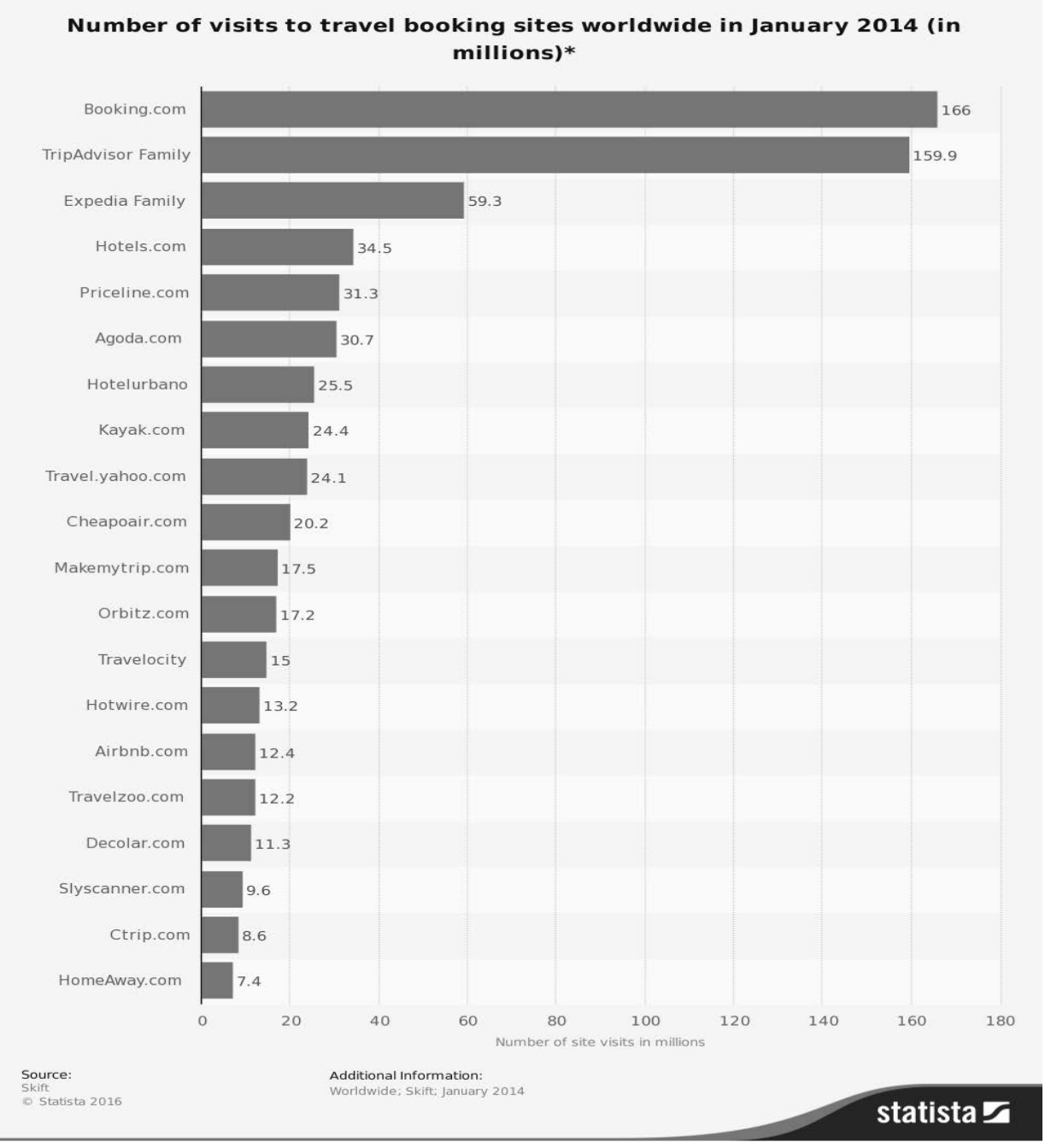

Izvor: Statista, https://www.statista.com/statistics/459983/number-of-visits-to-travel-booking-sites-worldwide/ 
Među hrvatskim online rezervacijskim sustavima najviše se ističu Adriatic.hr i Adriagate. com, a potonji ima posebnu kategoriju „agroturizam“ za pretraživanje.

Dobri primjeri online rezervacijskih sustava specijaliziranih za agroturizam postoje $u$ Italiji (http://www.sardinianatour.com/farm-holidays/sardinia/) i Cipru (https://www.agrotourism. com.cy/), a funkcioniraju kao svojevrsni destinacijski informacijski sustav. Slično se može pronaći na web-portalu Histrica (http://histrica.com/hr/) koji je prvenstveno destinacijski informacijski sustav gdje se, uz ostalo, može istražiti ponuda agroturizma u „plavoj Istri“ (priobalje) i „zelenoj Istri“ (unutrašnjost), a cjelokupni sadržaj je preveden na 4 jezika.

\section{2 Tržište online rezervacija u svijetu}

Online rezervacije čine 1/3 ukupnog tržišta putovanja. Rast online rezervacija ponajviše se očekuje u Kini, Indiji i Brazilu, dok u Europi prednjači Velika Britanija, a nakon nje slijede Njemačka i Francuska (Ružić et al., 2013). No u 2015. godini najveći prihodi od online rezervacija ostvareni su u Americi, zatim u Kini, Velikoj Britaniji, Njemačkoj i Francuskoj (Statista, 2017). „Prema istraživanju provedenom u Velikoj Britaniji na 2000 korisnika, gotovo 53\% korisnika je pronašlo i rezerviralo svoj smještaj putem interneta, dok je 30 \% korisnika prvo provelo internetsko istraživanje, a tada napravilo rezervaciju izvan interneta tj. putem telefona, e-poštom ili fizičkim odlaskom u poslovnicu. To znači da više od $80 \%$ posto turista koristi Internet da bi došlo do informacija o mogućnostima putovanja i smještaja stavljajući tako Internet kao najvažniji korak prilikom odlučivanja o rezervaciji." (Sambolić, 2011) Slično potvrđuje Eurostatovo izvješće o uporabi IKT-a u turizmu prema kojem je 55 \% rezervacija smještaja za sva putovanja stanovnika Europske unije napravljeno online, a za putovanja $u$ inozemstvo na online rezervacije otpada čak 59 \% (Eurostat, 2016). Postoje velike razlike u korištenju online rezervacija smještaja za putovanja među zemljama Europske unije, pa tako tu uslugu najviše koriste stanovnici Nizozemske (69 \%), Francuske (68 \%) i Luxemburga (67 \%) (Eurostat, 2016).

\section{UPORABA ONLINE REZERVACIJSKIH SUSTAVA U OBJEKTIMA RURALNOG I AGROTURIZMA U ISTRI}

Istraživanje koje će biti predstavljeno u ovom poglavlju provedeno je kako bi se ustanovilo u kojoj su mjeri informacije o objektima ruralnog i agroturizma u Istri i njihovih smještajnih kapaciteta dostupni zainteresiranim korisnicima putem interneta. Svrha istraživanja je utvrditi stupanj korištenja IKT-a, s naglaskom na uporabu online rezervacijskih sustava, $\mathrm{u}$ poslovanju agroturizama i ruralnih obiteljskih hotela u Istri.

\section{1 Metodologija istraživanja}

Problemsko područje ovog rada je uporaba e-poslovanja u specifičnom segmentu turističke ponude Istre. Ciljevi istraživanja su ustanoviti na koji način vlasnici agroturizma i ruralnih obiteljskih hotela u Istri prodaju svoje smještajne kapacitete i upravljaju rezervacijama, koje online rezervacijske sustave koriste i u kojoj su mjeri zadovoljni njima. Pretpostavka je da se putem online rezervacijskih sustava može rezervirati smještaj u manje od polovice objekata ruralnog i agroturizma u Istri. 
Istraživanje o uporabi online rezervacijskih sustava u objektima agroturizma u Istri provedeno je putem posebno dizajniranog online anketnog upitnika napravljenog u alatu Google Disk - Obrasci. Anketni upitnik sastoji se od 9 pitanja s ponuđenim odgovorima među kojima ispitanik bira samo jedan odgovor. Upitnik nije sadržavao pitanja o demografskim podacima ispitanika. Upitnik je poslan e-poštom na 42 adrese vlasnika agroturizama i ruralnih obiteljskih hotela u Istri čiji su kontakti javno dostupni na internetu. Istraživanju se odazvalo 19 ispitanika ili 45,24 \% stoga taj broj predstavlja uzorak istraživanja. Za analizu rezultata istraživanja korištena je metoda deskriptivne statistike.

\subsection{Analiza i interpretacija rezultata istraživanja}

Mrežne stranice jedan su od načina globalne promocije vlastite turističke ponude, pa se prvim anketnim pitanjem željelo saznati posjeduju li agroturistički objekti i ruralni obiteljski hoteli vlastite mrežne stranice, na što je potvrdno odgovorilo čak $79 \%$ ispitanika. Na pitanje postoji li mogućnost online rezervacije njihovih smještajnih kapaciteta, većina ispitanika $(84,2 \%)$ je odgovorila potvrdno, a samo 3 objekta (15,8\%) nemaju tu mogućnost. Tek kod 2 objekta iz uzorka (10,5 \%) moguće je direktno na njihovim mrežnim stranicama uplatiti rezervaciju smještaja nekim od oblika online plaćanja, dok ostali nemaju tu mogućnost.

Sljedećim anketnim pitanjem željelo se utvrditi putem kojih online rezervacijskih sustava ispitanici samostalno, tj. bez posrednika distribuiraju svoju turističku ponudu ivrše prodaju smještajnih kapaciteta. Uz pitanje dana je i uputa koja kazuje da ispitanik koji koristi više od jednog online rezervacijskog sustava treba odabrati onaj koji najčěćce koristi. Rezultati pokazuju (graf 2) da se najviše koristi Airbnb.com (25 \%), podjednaki udio imaju Booking.com i TripAdvisor (svaki po $20 \%$ ), dok $35 \%$ ispitanika ne koristi samostalno niti jedan online rezervacijski sustav. Airbnb.com nudi isključivo privatni smještaj, a razlog njegove popularnosti može biti i u tome što te mrežne stranice funkcioniraju kao društvena mreža, pa omogućuje korisnicima povezivanje s onima koji su već bili na određenoj destinaciji, razmjenu praktičnih savjeta, iskustava i lokalnih informacija koje inače ne pišu u vodičima (Žujo, 2013). Booking. com je na početku svog rada najviše zarađivao na hotelima, dok se danas sve više okreće privatnim iznajmljivačima, kao i TripAdvisor, a kod oba servisa bitna je pozicija, odnosno rang iznajmljivača, tj. njegove ponude i preporuke drugih gostiju, što se direktno odražava na prodaju.

Graf 2. Online rezervacijski sustavi korišteni u agroturizmu i ruralnim obiteljskim hotelima u Istri

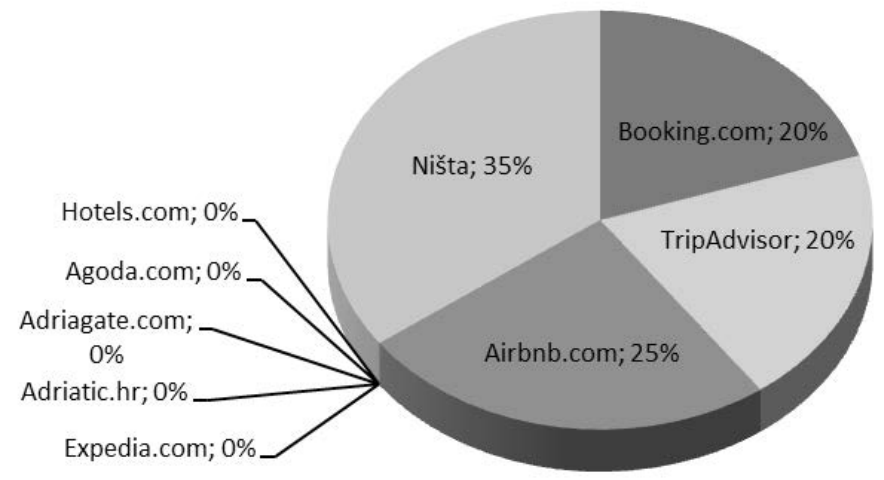


Svi ispitanici slažu se da su za današnje poslovanje u području turizma i hotelijerstva važni online rezervacijski sustavi, a aritmetička sredina odgovora na skali od 1 do 5 iznosi visokih 4,53. Najveći broj ispitanika $(68,4 \%)$ smatra da su online rezervacijski sustavi izuzetno važni za njihovo poslovanje, dok nitko ne smatra da su nedovoljno ili malo važni.

Nadalje, od ispitanika se tražilo da na skali od 1 do 5 ( 1 = vrlo nezadovoljan; 5 = izuzetno zadovoljan) izraze stupanj zadovoljstva samo s onim online rezervacijskim sustavom koji koriste u svom poslovanju. Rezultati prikazani grafom 3 pokazuju da su ispitanici najviše zadovoljni sustavom Airbnb.com, vrlo zadovoljni TripAdvisorom, a umjereno zadovoljni sustavom Booking. com. U prethodnom pitanju izjasnili su se da ne koriste ostale online rezervacijske sustave, već samo ova 3 navedena.

Graf 3. Zadovoljstvo online rezervacijskim sustavom

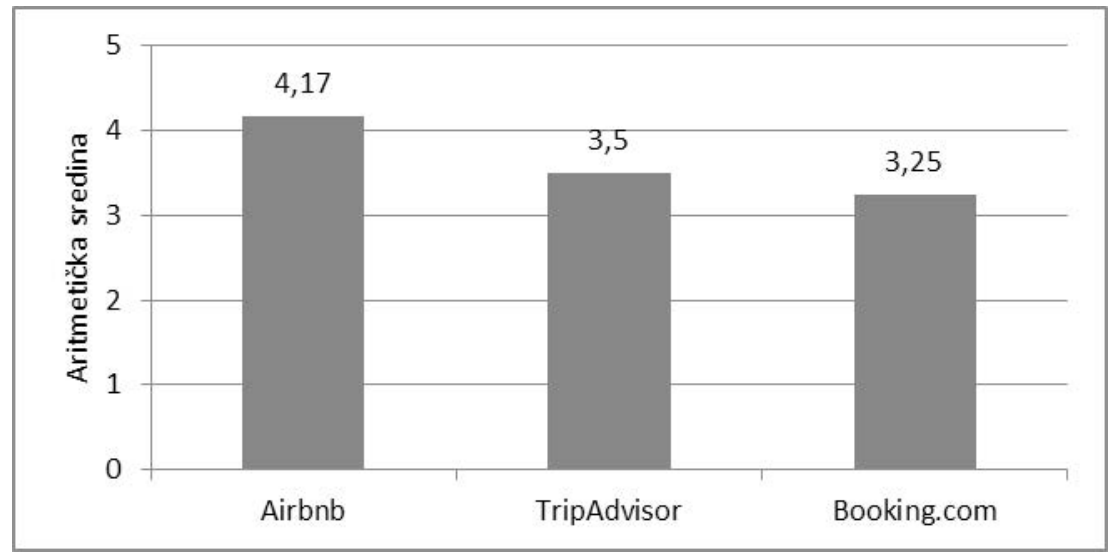

Izvor: obrada autora

Na pitanje vode li svoju evidenciju zauzetosti smještajnih kapaciteta i potvrđenih rezervacija u papirnatom obliku čak $79 \%$ ispitanika dalo je potvrdni odgovor. Isti je udio ispitanika (79 \%) koji koriste program za upravljanje rezervacijama, pa se može zaključiti da oni paralelno vode evidenciju o rezervacijama u papirnatom i digitalnom obliku. No $21 \%$ ispitanika ne koristi nikakav softver, odnosno cjelokupni posao upravljanja rezervacijama vlastitih smještajnih kapaciteta obavljaju ručno.

Posljednjim pitanjem utvrđeno je da 18 objekata iz uzorka (94,7 \%) nudi svojim gostima pristup bežičnom internetu (Wi-Fi), a samo 1 objekt nema tu mogućnost.

\section{ZAKLJUČAK}

Online rezervacijski sustavi veoma su bitni u svakodnevnom poslovanju turističkih subjekata, a iznimno su važni za male poduzetnike, kao što su to vlasnici agroturizma i ruralnih obiteljskih hotela u Istri. Online rezervacijskim sustavima ponude iznajmljivača dopiru do velikog broja ljudi te nisu ograničene prostorno ni vremenski. Potencijalnim gostima lakše je planirati i rezervirati odmor ili putovanje internetom, iz udobnosti vlastitog doma, bilo koji dan u tjednu (24/7), jednostavno 
mogu uspoređivati ponude i cijene, te steći realnu sliku o smještaju i destinaciji čitajući preporuke ostalih gostiju. Da bi ponudili vlastite smještajne kapacitete, vlasnici objekata agroturizma i ruralnih obiteljskih hotela u Istri koriste sustav Airbnb, TripAdvisor.com i Booking.com kojima su veoma zadovoljni. Navedene rezervacijske sustave koristi $65 \%$ objekata ruralnog i agroturizma uključenih $\mathrm{u}$ istraživanje, a putem online rezervacijskog sustava moguće je rezervirati smještaj u $84 \%$ njih. lako čak $35 \%$ ispitanika ne koristi online rezervacijski sustav, i oni uviđaju važnost takvih sustava za svoje poslovanje. Pohvalno je da velik udio takvih objekata ima vlastite mrežne stranice, tako da se potencijalni turisti mogu informirati o bogatoj ponudi agroturizma i ruralnog turizma u Istri i stupiti u kontakt s vlasnicima. lako je moto ruralnog i agroturizma povratak u prirodu i zbližavanje s njom, vlasnici takvih objekata prepoznaju trendove i potrebe svojih korisnika pa $95 \%$ njih nudi mogućnost korištenja interneta gostima. Budući da je sve veći interes stranih i domaćih gostiju za ruralnim i agroturizmom u Istri, potrebno je raditi na promociji takve ponude diljem svijeta, a jedan od načina je uporaba poznatih i široko prihvaćenih online rezervacijskih sustava. Međutim, da cjelokupna ponuda ruralnog i agroturizma Istre bude prepoznatljiva i dohvatljiva na jednom mjestu u virtualnom okruženju, potreban je specijalizirani, višejezični online rezervacijski sustav prilagođen i za mobilne uređaje, koji će okupiti takve iznajmljivače i ugostitelje te biti posrednik između njih i potencijalnih posjetitelja.

\section{LITERATURA}

BookingIT (2007). E-booking. http://www.booking-it.com/ (10. 1. 2017.).

Državni zavod za statistiku RH (2015). Primjena informacijskih i komunikacijskih tehnologija (IKT) u kućanstvima i kod pojedinaca u 2015. (prvi rezultati). http://www.dzs.hr/Hrv_Eng/publication/2015/02-03-02_01_2015.htm (12. 1. 2017.)

Eurostat (2016). Statistics of ICT use in tourism. http://ec.europa.eu/eurostat/statistics-explained/index.php/Statistics on_ICT_use_in_tourism (10.1.2017.)

Galičić, V., Ivanović, S., Lupić, M (2005). Hotelska prodaja i recepcijsko poslovanje. Sveučilište u Rijeci, Fakultet za turistički i hotelski menadžment u Opatiji.

Kliček, B. (2008). eTurizam u svijetu i u Hrvatskoj. Info Trend. http://www.infotrend.hr/clanak/2008/5/eturizam-u-svijetui-hrvatskoj,12,288.html (10. 1. 2017.)

Ministarstvo turizma Republike Hrvatske (2016). Turizam u brojkama 2015. www.mint.hr (9. 2. 2017.).

Ružić, D., Biloš, A., Kelić, I. (2013). Rezervacijski sustavi na internetu. Ekonomski fakultet u Osijeku. http://www.efos.unios. hr/e-marketing/wp-content/uploads/sites/5/2013/04/e-marketing2013-11-rezervacijski-sustavi.pdf (9. 1. 2017.)

Sambolić, S. (2011). Izrada rezervacijskih sustava u turizmu. Oxidian.hr. http://oxidian.hr/kvalitetne-informacije-nasvakom-koraku-2-dio-clanka/ (10. 1. 2017.)

Sarjanović, I. (2004). Ruralni turizam u Istri- dokaz da hrvatski turizam može i na drugi način. Geografija.hr. http://www. geografija.hr/hrvatska/ruralni-turizam-u-istri-dokaz-da-hrvatski-turizam-moze-i-na-drugi-nacin/ (28. 12. 2016.)

Statista (2017). Online travel booking ravenue in selected countries worldwide in 2015. https://www.statista.com/ statistics/516590/global-comparison-online-travel-booking-revenue-digital-market-outlook/ (12. 1. 2017.)

Vrdoljak-Šalamon, B. (2015). Hrvatski turizam u brojkama. Institut za turizam, Zagreb. http://www.iztzg.hr/UserFiles/file/ institut/Hrvatski-turizam-u-brojkama-2015-Broj-01.pdf (12. 1. 2017.)

Žujo, M. (2013). Airbnb.com postaje zvijezda među turističkim servisima. Poslovni.hr, http://www.poslovni.hr/after5/ airbnbcom-postaje-zvijezda-meu-turistickim-servisima-250265 (13. 1. 2017.) 


\title{
USE OF ONLINE BOOKING SYSTEMS IN ISTRIAN AGRITOURISM ${ }^{4}$
}

\begin{abstract}
This paper focuses on the application of ICT in tourism, i.e. it examines the use of online booking systems in terms of offer of accommodation capacities in agritourism and rural family hotels in Istria. This research seeks to determine how the owners of rural family hotels and agritourism sell their accommodation capacities and manage their bookings, what online booking systems they use and whether they find them satisfactory. In the theoretical part of this paper, the advantages of ICT in the business processes in tourism are presented with the emphasis on the computerization of booking offices of hotel accommodation capacities and the emergence of online booking systems. The advantages of online booking systems for business entities and end users are analyzed. Relevant research shows growth in the online booking market around the world, which is consequently also reflected on tourism in Croatia. However, the most popular online booking systems like Booking.com, TripAdvisor, Expedia, Hotels.com, Agoda and others offer mostly hotel accommodation followed by private apartment accommodation, and usually there is no search category for agritourism and rural tourism facilities. Unlike other booking systems, Airbnb.com, offers exclusively private accommodation. It is the most widely used booking system by the agritourism and rural family hotel owners in Istria for the distribution of their tourist offer and the selling of their accommodation capacities, followed by Booking.com and TripAdvisor. This research has shown that the agritourism and rural family hotel facilities in Istria are widely available online via owners' web pages, with $84 \%$ of these facilities available for online bookings. The participants have expressed high satisfaction with the online booking system they use, although many of them keep records of the bookings in the written form as well.
\end{abstract}

Keywords: agritourism, online booking system, Booking.com, Airbnb, TripAdvisor

MSc., Senior Lecturer, Polytechnic of Rijeka, Vukovarska 58, 51000 Rijeka, Croatia. E-mail: elena@veleri.hr Bacc.oec., E-mail: zupicicluana@gmail.com

MSc., Senior Lecturer, Polytechnic of Rijeka, Vukovarska 58, 51000 Rijeka, Croatia. E-mail: jasminka.tomljanovic@veleri.hr

Received: 15 January 2017; Accepted: 15 February 2017 
